\title{
Correction to: Monitoring and prediction of hurricane tracks using GPS tropospheric products
}

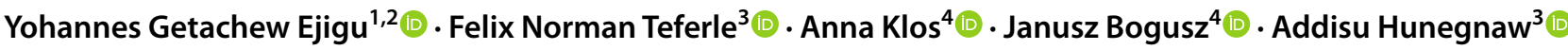

Published online: 20 May 2021

(c) Springer-Verlag GmbH Germany, part of Springer Nature 2021

\section{Correction to: GPS Solutions (2021) 25:76 \\ https://doi.org/10.1007/s10291-021-01104-3}

In the original article published, the given name and the family name of the fourth author are swapped. The correct name is Janusz Bogusz.

Additionally, the funding information is deleted from the article.

The original article has been corrected.

Publisher's Note Springer Nature remains neutral with regard to jurisdictional claims in published maps and institutional affiliations.

The original article can be found online at https://doi.org/10.1007/ s10291-021-01104-3.

Yohannes Getachew Ejigu

john.yohannes200@gmail.com

1 Department of Space Science and Application Research Development, Ethiopian Space Science and Technology Institute (ESSTI), Addis Ababa, Ethiopia

2 Department of Physics, Wolkite University, Wolkite, Ethiopia

3 Institute of Civil and Environmental Engineering, University of Luxembourg, Luxembourg, Luxembourg

4 Faculty of Civil Engineering and Geodesy, Military University of Technology, Warsaw, Poland 